\title{
Adolescent Sexual and Reproductive Health in Developing Countries: An Overview of Trends and Interventions
}

By Michelle J. Hindin and Adesegun O. Fatusi

Michelle J. Hindin is associate professor, Department of Population, Family and Reproductive Health, Johns Hopkins Bloomberg School of Public Health, Baltimore, MD, USA.

Adesegun O. Fatusi is associate professor, Department of Community Health, College of Health Sciences, Obafemi Awolowo University, Ile-Ife, Nigeria.
Today there are more than one billion $10-19$ year olds, ${ }^{1}$ $70 \%$ of whom live in developing nations. ${ }^{2}$ They are growing up in circumstances quite different from those of their parents, with greater access to formal education, increasing need for such technological skills as computer and internet literacy, different job opportunities, and more exposure to new ideas through media, telecommunications and other avenues. ${ }^{2}$

The environment in which young people are making decisions related to sexual and reproductive health is also rapidly evolving. Rates of sexual initiation during young adulthood are rising or remaining unchanged in many developing countries, ${ }^{3,4}$ childbearing and marriage are increasingly unlinked, ${ }^{5}$ and in many countries, high HIV prevalence adds to the risks associated with early sexual activity. ${ }^{6,7}$ For example, in all but a few countries in SubSaharan Africa, AIDS is a generalized epidemic. Young people are disproportionately affected, accounting for almost two-thirds of the people living with HIV in the region. Moreover, the prevalence of HIV among adolescents is higher in Sub-Saharan Africa than in other parts of the world. ${ }^{8}$

Because most youth obtain at least some education, ${ }^{9}$ particularly with the international recognition of the importance of schooling (e.g., the Millennium Development Goals), school-based programs appear to be a logical choice for sexual and reproductive health education. However, according to recent reviews of school-based HIV interventions, such programs have had mixed results. ${ }^{10-12}$ In addition, such interventions miss adolescents who are not in school. At the same time, the provision of comprehensive sexual and reproductive health interventions in developing countries has been impeded by ideologically driven restrictions. ${ }^{13}$ Many community-based programs have had to focus on HIV prevention rather than comprehensive sexual and reproductive health, again because of funding restrictions.

Another potential avenue for improving sexual and reproductive health outcomes for young people is parentchild communication. However, most of today's parents were not taught about sexual and reproductive health by their own parents or even in school, leaving them unable

*Ironically, in some developing country settings, later marriage is also a risk factor for HIV acquisition, as it extends the period during which a young woman may be exposed to premarital sex and may increase her number of premarital partners (sources: Adair T, HIV status and age at first marriage among women in Cameroon, Journal of Biosocial Science, 2008, 40(5):743-760; and Bongaarts J, Late marriage and the HIV epidemic in Sub-Saharan Africa, Population Studies, 2007,61(1):73-83). to pass on crucial knowledge to their children. The discomfort many parents feel about talking to their children about sexuality further impedes their ability to provide guidance.

\section{EARLY MARRIAGE AND SEXUAL ACTIVITY}

Early marriage and early marital sexual activity present reproductive health risks for young women. Early marriage can lead to pregnancies that put young women at risk for obstetric fistulae, ${ }^{14}$ and can be a risk factor for HIV infection. ${ }^{* 15}$ The risks for young girls conferred by early marriage may involve older male partners-who have often been sexually active for many years-"bringing" HIV to the marriage. Thus, evidence suggesting that age at marriage is rising in most developing country settings ${ }^{16}$ is welcome; not so welcome, however, is evidence that the proportion of young people engaging in premarital sexual activity is also increasing. ${ }^{17}$

Adolescent sexual activity, within or outside of marriage, can lead to negative reproductive health outcomes. ${ }^{18}$ Unprotected sexual activity can expose young women to the risks of unintended pregnancy, unwanted childbearing and abortion, as well as HIV and other STIs. In addition to being a human rights concern, coerced or unwanted sex is associated with these same adverse reproductive health outcomes. ${ }^{19-23}$ Findings from a nationally representative sample of females aged 13-24 in Swaziland, for example, indicated that $33 \%$ had experienced sexual violence before the age of $18 .{ }^{24}$ This prevalence falls within the reported range for other Sub-Saharan African countries. ${ }^{25}$ Sexual coercion has also been reported by boys in Africa ${ }^{26}$ and other developing country settings. ${ }^{27}$

The outcomes related to early sexual activity are not just health-related and are often complex. For example, at least in some settings, adolescents who stay in school longer are less likely to engage in sexual risk behaviors. ${ }^{28}$ It is unclear, however, whether adolescents who stay in school are less likely to engage in risky sex or whether sexually active adolescents who engage in risky sex are more likely than others to drop out of school, and are missed in schoolbased studies.

In some settings where premarital sex is taboo, sexual activity may be distracting or provoke negative responses from teachers, adversely affect school performance and lead to dropout. ${ }^{29}$ Moreover, sexual activity may result in adolescent pregnancy and birth, and thereby lead to school dropout or expulsion, since the school policy in many developing countries is unfriendly to pregnant 
adolescents. (Nevertheless, when pregnant girls leave school, pregnancy may not be the primary reason. ${ }^{30}$ ) Thus teenage sexual activity-whether or not it leads to pregnancy or birth-may have a negative impact on young women's future educational attainment through school dropout. Marriage may also lead to school dropout, even if the young woman does not become pregnant. ${ }^{31}$

Most men and women become sexually active during adolescence. $^{32}$ Recent evidence from the Demographic and Health Surveys and the AIDS Indicators Surveys ${ }^{16}$ show that median age at first sex among 20-24-year-old women ranges from a low of 16 years or younger in Chad, Mali and Mozambique to a high of 19.6 in Senegal. Overall, the median age in the rest of Sub-Saharan Africa is about 18.5 years. Among young men of the same agegroup in Sub-Saharan Africa, the median age at first sex ranges from a low of 16.9 in Mozambique to a high of 19.6 in Ghana. Other recent studies show even younger median ages of first sex in some countries in Sub-Saharan Africa. ${ }^{33,34}$ The pattern of age at sexual debut in SubSaharan Africa generally contrasts with that in other parts of the developing world. In Latin America and the Caribbean, half of young women were between 18 and 19 at first sex. Limited data are available for men's age at sexual debut, but in Bolivia, Guyana and the Dominican Republic men were younger than women at first sex. ${ }^{16}$

Physical maturation occurs earlier in young women than in young men, but psychological and emotional readiness for the potential consequences of sexual activity occur much later than menarche. In some settings, young men have sex before reaching physical maturity; doing so is often related to engaging in high-risk or harmful behaviors. ${ }^{18}$

\section{ADOLESCENT CONTRACEPTIVE USE AND PREGNANCY}

Use of modern contraceptives, particularly among married youth in Sub-Saharan Africa, is very low-women who are married, even as adolescents, are expected to have children right away. In many developing country settings, particularly Sub-Saharan Africa, women's gender identities and social status are tied to motherhood ${ }^{35}$ and childlessness is highly stigmatized. 36,37

Among unmarried sexually active adolescents in SubSaharan Africa, contraceptive use ranges from a low of 3\% in Rwanda to a high of 56\% in Burkina Faso. ${ }^{16}$ Unmet need for contraception, or nonuse of methods despite the desire to limit births or delay them for at least two years, is high among unmarried adolescents in Sub-Saharan Africa (more than $40 \%$ in most countries). In comparison, $10-31 \%$ of unmarried adolescents in Latin America are considered to have unmet need. ${ }^{16}$

As expected, unmet need among married adolescents is lower, but still substantial. ${ }^{10}$ Recent evidence suggests that in Sub-Saharan Africa, and in South and South East Asia, more than 20\% of 15-19-year-old women have been pregnant; although a majority of these women are married, more than $10 \%$ of adolescent pregnancies in the Demo- cratic Republic of Congo, Madagascar, Mozambique and Zambia are nonmarital; while in the rest of Sub-Saharan Africa and Latin America, nonmarital pregnancy rates are below $10 \% .^{16}$

Adolescents have unprotected sex for a multitude of reasons. Within or outside of marriage, young women may feel pressure to prove their fertility. Other young people may engage in unprotected sex because they have not considered contraception, ${ }^{38}$ fear possible side effects, ${ }^{39}$ are misinformed about the risk of pregnancy or STIs posed by unprotected $\operatorname{sex}^{40}$ or are more concerned with the safety of condoms than the safety of an unintended pregnancy. ${ }^{41}$

\section{ADOLESCENT HIGH-RISK BEHAVIORS AND HIV}

Young women are less likely than young men to engage in high-risk sexual behaviors. In Sub-Saharan Africa, among young men who had ever had sexual intercourse, more than $20 \%$ of them had had multiple partners in the past 12 months, compared with fewer than $10 \%$ of young women. Although data are more limited for Latin America, $5 \%$ of women or fewer report multiple partners except in Colombia, where $8 \%$ of women report multiple partners in the past year. In contrast, 19\% of Guyanese men, and more than $30 \%$ of Bolivian and Dominican men, report multiple partners. ${ }^{16}$

Evidence from Sub-Saharan Africa and Latin America suggests that condom use at last sex has increased among adolescents, ${ }^{17}$ but levels of use are still not sufficient to substantially reduce the spread of HIV. ${ }^{5}$

\section{ENHANCING COMMUNICATION: EVIDENCE FROM INTERVENTIONS}

Today's adolescents will determine the social fabric, economic productivity, and reproductive health and wellbeing of nations throughout the world in the coming decades. Worldwide, a variety of programs have tried to address the sexual and reproductive health needs of adolescents. Communications and other interventions designed to improve the sexual and reproductive health of adolescents need to respond appropriately to the changing global context.

A systematic review of school-based sexual health interventions in Sub-Saharan Africa found only 12 articles meeting its criteria for inclusion, reflecting limited evidence of evaluation of school-based programs. ${ }^{10}$ In terms of impact, most interventions led to an improvement in knowledge, attitudes and intentions, but few found evidence of lasting behavioral changes. ${ }^{10}$ In a school-based intervention in Thailand, secondary students who were exposed to a comprehensive sex education program had greater knowledge than other students, and were more likely to intend to refuse sex and to decrease frequency of sex, but no change was seen in consistent condom use. ${ }^{42}$ In Nigeria, ${ }^{43}$ a randomized school-based intervention with nurses led to more favorable attitudes toward HIV prevention measures among students. A study in the Dominican Republic showed that adolescents who received sex education had 
higher rates of condom use and more knowledge of HIV than those who did not, ${ }^{44}$ while studies in Mexico found that a school-based intervention led to more positive norms related to HIV-preventive behaviors. ${ }^{45,46}$

Community-based sex education interventions have also shown mixed results. In a cluster-randomized study in South Africa, the incidence of herpes simplex infection was lower among youth who received a 50-hour program than among those who did not, but the incidence of HIV was not. Males reported lower rates of transactional sex, but females reported increased rates. ${ }^{47}$ In Taiwan, in contrast, a 48-month community program to promote contraception showed a positive, but limited impact on contraceptive adoption among unmarried youth. ${ }^{48} \mathrm{~A}$ recent review including developing and developed nations found that peer-led sex education interventions had a limited impact on condom use, pregnancy or getting a new sexual partner. ${ }^{49}$

Several recent studies have examined the impact of parent-child communication, but only one evaluated the impact of parent-child communication about sex on adolescent outcomes in developing countries. Conducted in South Africa, this study showed that women who were part of a multifaceted intervention were more likely than those who were not to report communication with their children and other members of their household about issues related to sex and condom use, rather than just about the dangers of sex. ${ }^{50}$ A study in Ghana showed that schoolgoing youth who reported parent-child communication about HIV/AIDS were more likely to have used condoms at last sex, but communication was not associated with onset of sexual activity. ${ }^{51}$ A longitudinal study of 12-14year-old virgins in Tanzania showed that 27\% reported talking to their parents about sex and HIV, but that these discussions were not associated with the timing of sexual initiation. Interestingly, however, communication with teachers was associated with delayed sexual initiation. ${ }^{52}$ In some developing country settings, parents were among the most utilized ${ }^{53,54}$ or preferred sources of sexual and reproductive health information. ${ }^{55}$

\section{FUTURE STEPS IN RESEARCH AND PROGRAMS}

In many settings, high rates of HIV prevalence, along with early sexual debut and multiple partnerships, have led researchers to conclude that there is a need for sexual and reproductive health education comprising more than messages promoting abstinence. ${ }^{5,56,57}$ Well-designed impact evaluations are needed to provide evidence about the quality and content of interventions. Many of the adolescents at greatest risk are missed by school-based programs because they are no longer in school..$^{5}$ Therefore, it is important to target both in-school and out-of-school youth. In addition, research on the impact of parent-child communication needs to examine concordance between what parents believe they are saying to their adolescents and what messages and information adolescents are receiving from these interactions. Finally, carefully collected longitudinal data are needed, because programs may be initiated after sexual activity has begun-leading to incorrect assumptions that programs increase adolescent risk behavior.

Gaps still exist within programs that target both knowledge and behavior change in the sexual activities of adolescents. Programs need to go beyond HIV and focus on broader topics in sexual and reproductive health-currently, in many programs, other STIs and pregnancy prevention are conspicuously absent. In addition, gender differences need greater attention. Given gender differences in behavior as well as in some of the consequences of sexual activity, communication from any reliable source on sexual and reproductive health needs not only to be gender-sensitive, but to empower adolescents, particularly young women, to negotiate behavior on the basis of accurate information. ${ }^{32}$

After years of funding being limited to abstinence-only education, ${ }^{58}$ scientific evidence on whether educating adolescents about sexual behavior, contraception and STIs influences young people to engage in high-risk sexual behaviors is finally being considered. It is evident that neither the abstinence-only nor the ABC (abstinence, be faithful, use condoms) focus of the last few years has brought about the desired outcomes for adolescent sexual and reproductive health. Given that no single educational or communication program appears to lead to lasting behavior change, a stronger focus on behavior is crucial.

With the largest cohort of young people in history, it is essential to continue to carefully design interventions and review their impact to assure that adolescents have the tools to make informed and healthy choices concerning their sexual and reproductive health.

\section{REFERENCES}

1. United Nations Population Fund (UNFPA), State of the World Population 2003: Investing in Adolescents' Health and Rights, New York: UNFPA, 2003

2. UNFPA, Generation of Change: Young People and Culture, 2008, Youth Supplement to UNFPA's State of the World Population Report, New York: UNFPA, 2008

3. Ali MM and Cleland J, Sexual and reproductive behaviour among single women aged 15-24 in eight Latin American countries: a comparative analysis, Social Science \& Medicine, 2005, 60(6):1175-1185.

4. Gupta N and Mahy M, Sexual initiation among adolescent girls and boys: trends and differentials in Sub-Saharan Africa, Archives of Sexual Behavior, 2003, 32(1):41-53.

5. Bearinger LH et al., Global perspectives on the sexual and reproductive health of adolescents: patterns, prevention, and potential, Lancet, 369(9568):1220-1231.

6. Pettifor AE et al., Early age of first sex: A risk factor for HIV infection among women in Zimbabwe, AIDS, 2004, 18(10):1435-1442.

7. Dixon-Mueller R, Starting young: sexual initiation and HIV prevention in early adolescence, AIDS and Behavior, 2009, 13(1):100-109.

8. Joint United Nations Programme on HIV/AIDS, (UNAIDS), HIV and young people: the threat for today's youth, 2004 Report on the Global AIDS Epidemic, fourth ed., Geneva, Switzerland: UNAIDS, 2004, pp. 93-98.

9. United Nations (UN), The Millenium Development Goals Report 2008, UN: New York, 2008.

10. Paul-Ebhohimhen VA, Poobalan A and Van Teijlingen ER, A 
systematic review of school-based sexual health interventions to prevent STI/HIV in Sub-Saharan Africa, BMC Public Health, 2008, Vol. 8 , Art. 4.

11. Kirby D, Obasi A and Laris BA, The effectiveness of sex education and HIV education interventions in schools in developing countries, in: Ross DA, Dick B and Ferguson J, eds., Preventing HIV/AIDS in Young People. A Systematic Review of the Evidence from Developing Countries, WHO Technical Report, Geneva: World Health Organization, 2006, No. 938 , pp. 103-150.

12. Kirby DB, Laris BA and Rolleri LA, Sex and HIV education programs: their impact on sexual behaviors of young people throughout the world, Journal of Adolescent Health, 2007, 40(3): 206217.

13. Cleland J and Ali MM, Sexual abstinence, contraception, and condom use by young African women: a secondary analysis of survey data, Lancet, 2006, 368(9549):1788-1793.

14. Zheng AX and Anderson FWJ, Obstetric fistula in low-income countries, International Journal of Gynecology and Obstetrics, 2009 , 104(2):85-89

15. Clark S, Early marriage and HIV risks in Sub-Saharan Africa, Studies in Family Planning, 2004, 35(3):149-160.

16. Khan S and Mishra V, Youth Reproductive and Sexual Health, DHS Comparative Reports, Calverton, MD, USA: Macro International, Inc., 2008, No. 19.

17. Wellings K et al., Sexual behaviour in context: a global perspective, Lancet, 2006, 368(9548):1706-1728.

18. Dixon-Mueller R, How young is "too young"? comparative perspectives on adolescent sexual, marital, and reproductive transitions, Studies in Family Planning, 2008, 39(4):247-262.

19. Koenig MA et al., Coerced first intercourse and reproductive health among adolescent women in Rakai, Uganda, International Family Planning Perspectives, 2004, 30(4):156-163.

20. Maharaj P and Munthree C, Coerced first sexual intercourse and selected reproductive health outcomes among young women in KwaZulu-Natal, South Africa, Journal of Biosocial Science, 2007, 39(2):231-244.

21. Williams CM, McCloskey LA and Larsen U, Sexual violence at first intercourse against women in Moshi, northern Tanzania: prevalence, risk factors, and consequences, Population Studies, 2008, 62(3): 335-348.

22. Zablotska IB et al., Alcohol use, intimate partner violence, sexual coercion and HIV among women aged 15-24 in Rakai, Uganda, AIDS and Behavior, 2009, 13(2):225-233.

23. Polis $\mathrm{CB}$ et al., Coerced sexual debut and lifetime abortion attempts among women in Rakai, Uganda, International Journal of Gynecology \& Obstetrics, 2009, 104(2):105-109.

24. Reza A et al., Sexual violence and its health consequences for female children in Swaziland: a cluster survey study, Lancet, 2009, (forthcoming)

25. Moore AM et al., Coerced first sex among adolescent girls in SubSaharan Africa: prevalence and context, African Journal of Reproductive Health, 2007, 11(3):62-82.

26. Ajuwon AJ et al., Sexual behavior and experience of sexual coercion among secondary school students in three states in North Eastern Nigeria, BMC Public Health, 2006, Vol. 6, Art. 310

27. Jaya J and Hindin MJ, Nonconsensual sexual experiences of adolescents in urban India, Journal of Adolescent Health, 2007, 40(6):573.e7-573.el4

28. Hargreaves JR et al., The association between school attendance, HIV infection and sexual behaviour among young people in rural South Africa, Journal of Epidemiology and Community Health, 2008, 62(2):113-119.

29. Biddlecom A et al., Associations between premarital sex and leaving school in four Sub-Saharan African countries, Studies in Family
Planning, 2008, 39(4):337-350

30. Lloyd CB and Mensch BS, Marriage and childbirth as factors in dropping out from school: an analysis of DHS data from Sub-Saharan Africa, Population Studies, 2008, 62(1):1-13.

31. Grant MJ and Hallman KK, Pregnancy-related school dropout and prior school performance in KwaZulu-Natal, South Africa, Studies in Family Planning, 2008, 39(4):369-382

32. Glasier A et al., Sexual and reproductive health: a matter of life and death, Lancet, 2006, 368(9547):1595-1607.

33. Kayembe KP et al., Correlates of ever had sex and of recent sex among teenagers and young unmarried adults in the Democratic Republic of Congo, AIDS and Behavior, 2008, 12(4):585-593.

34. Tenkorang EY and Maticka-Tyndale E, Factors influencing the timing of first sexual intercourse among young people in Nyanza, Kenya, International Family Planning Perspectives, 2008, 34(4):177-188.

35. Cooper D et al., "Life is still going on": reproductive intentions among HIV-positive women and men in South Africa, Social Science \& Medicine, 2007, 65(2):274-283.

36. Dodoo FNA and Frost AE, Gender in African population research the fertility/reproductive health example, Annual Review of Sociology, 2008, Vol. 34, pp. 431-452.

37. Dyer SJ, The value of children in African countries-insights from studies on infertility, Journal of Psychosomatic Obstetrics and Gynecology, 2007, 28(2):69-77.

38. Gomes KRO et al., Contraceptive method use by adolescents in Brazilian state capital, Journal of Pediatric and Adolescent Gynecology, 2008, 21(4):213-219.

39. Abiodun OM and Balogun O, Sexual activity and contraceptive use among young female students of tertiary educational institutions in Ilorin, Nigeria, Contraception, 2009, 79(2):146-149.

40. Adedimeji AA, Omololu FO and Odutolu O, HIV risk perception and constraints to protective behaviour among young slum dwellers in Ibadan, Nigeria, Journal of Health, Population and Nutrition, 2007, 25(2):146-157.

41. Warenius L et al., Vulnerability and sexual and reproductive health among Zambian secondary school students, Culture, Health and Sexuality, 2007, 9(5):533-544.

42. Thato R, Jenkins RA and Dusitsin N, Effects of the culturallysensitive comprehensive sex education programme among Thai secondary school students, Journal of Advanced Nursing, 2008, 62(4): 457-469.

43. Akpabio II et al., Effects of school health nursing education interventions on HIV/AIDS-related attitudes of students in Akwa Ibom State, Nigeria, Journal of Adolescent Health, 2009, 44(2):118-123.

44. Minaya J, Owen-Smith A and Herold J, The impact of sex education on HIV knowledge and condom use among adolescent females in the Dominican Republic, International Journal of Adolescent Medicine and Health, 2008, 20(3):275-282.

45. Givaudan M et al., Longitudinal study of a school based HIV/AIDS early prevention program for Mexican adolescents, Psychology, Health and Medicine, 2008,13(1):98-110.

46. Pick $S$ et al., Communication as a protective factor: evaluation of a life skills HIV/AIDS prevention program for Mexican elementaryschool students, AIDS Education and Prevention, 2007, 19(5):408-421.

47. Jewkes R et al., Impact of stepping stones on incidence of HIV and HSV-2 and sexual behaviour in rural South Africa: cluster randomised controlled trial, BMJ, 2008, 337(7666):391-395.

48. Tu X et al., Long-term effects of a community-based program on contraceptive use among sexually active unmarried youth in Shanghai, China, Journal of Adolescent Health, 2008, 42(3):249-258

49. Kim CR and Free C, Recent evaluations of the peer-led approach in adolescent sexual health education: a systematic review, International Family Planning Perspectives, 2008, 34(2):89-96.

50. Phetla G et al., "They have opened our mouths": increasing women's skills and motivation for sexual communication with young 
people in rural South Africa, AIDS Education and Prevention, 2008, 20(6):504-518.

51. Adu-Mireku S, Family communication about HIV/AIDS and sexual behaviour among senior secondary school students in Accra, Ghana, African Health Sciences, 2003, 3(1):7-14.

52. Kawai K et al., Parents' and teachers' communication about HIV and sex in relation to the timing of sexual initiation among young adolescents in Tanzania, Scandinavian Journal of Public Health, 2008, 36(8):879-888.

53. Ybarra ML et al., Health information seeking among Mbararan adolescents: results from the Uganda Media and You survey, Health Education Research, 2008, 23(2):249-258.

54. Nwagwu WE, The internet as a source of reproductive health information among adolescent girls in an urban city in Nigeria, BMC Public Health, 2007, Vol. 7, Art. 354.

55. Mbonile L and Kayombo EJ, Assessing acceptability of parents/ guardians of adolescents towards introduction of sex and reproductive health education in schools at Kinondoni Municipal in Dar es Salaam city, East African Journal of Public Health, 2008, 5(1):26-31.

56. Bersamin MM et al., Defining virginity and abstinence: adolescents' interpretations of sexual behaviors, Journal of Adolescent Health, 2007, 41(2):182-188.

57. Masatu MC et al., Predictors of risky sexual behavior among adolescents in Tanzania, AIDS and Behavior, 2009, 13(1):94-99

58. Santelli J et al., Abstinence-only education policies and programs: a position paper of the Society for Adolescent Medicine, Journal of Adolescent Health, 2006, 38(1):83-87. 